\title{
O monstro à mostra: mostruário
}

A beleza formal das figuras divinas e o equilibrio elegante entre as fés cristã e pagã não podem nos levar a ignorar que até mesmo na Itália, por volta de 1520, ou seja, na época da arte mais criativa e mais livre, a Antiguidade era venerada sob o signo de um Hermes duplo, apresentando, por um lado, um rosto sombrio e demoníaco que exigia uma cultuação supersticiosa, e, por outro, uma face olímpica e alegre que ocasionava uma devoção estética.

Aby Warburg

No dia de hoje, quinta-feira, 8 de junho de 2017, um conhecido jornal editado na capital paulista traz, como manchete, a notícia do descobrimento de fósseis, no Marrocos, que sugerem ter o Homo sapiens vivido no norte da África já há aproximadamente 300.000 anos, e não há apenas 200.000, como até agora se acreditou ${ }^{1}$. Caso as datações sejam comprovadas pelo rigor da ciência, a ocasião de nosso natalício pode ser lançada radicalmente para trás. Ficaremos 100.000 anos mais velhos. Isso implica que ficamos mais sábios ainda?

A chamada na primeira página do jornal traz entre suas ilustrações dois desenhos de crânios, visto um deles de perfil, o outro obliquamente. As legendas que os acompanham destacam diferenças de imediato notáveis com relação aos extintos neandertais: no perfil, o crânio alongado indica a possibilidade de uma muito maior quantidade de massa cerebral; na vista oblíqua, a face, em que a mandíbula se retrai e tende a alinhar-se com o eixo vertical proveniente da projeção da superfície da testa, com a qual podemos nos reconhecer. Eis-nos assim, e já desde então, distintamente distintos. Não mais animalescos, não mais primitivos, não mais monstruosos. Sábios inelutáveis.

Para além das aparências, em desenhos como tais figuram, mesmo que implicitamente, essências, algo típico de predicados
1. "Homo sapiens pode ter vivido 100 mil anos antes", em Folha de São Paulo, 08/06/2017, p. A1. 
2. DERRIDA, Jacques. La bestia y el soberano (Vol. I: 2001-2002), ed. Michel Lisse, Marie-Louise Mallet e Ginette Michaud. Tradução de Cristina de Peretti e Delmiro Rocha. Buenos Aires: Manantial, 2010.

3. BLANCHOT, Maurice. "O indestrutível”. A conversa infinita (A experiência limite). Tradução de João Moura Jr. São Paulo: Escuta, 2007; p. 69-87. sintéticos, tautológicos e teleológicos: o Homo sapiens é, com efeito, pai do Homo sapiens sapiens com que nós, plenos de modernidade, nos definimos. Depreende-se um evidente acento platônico, que de mais a mais pretende aniquilar o plutônico, e o inferno por este ante nós aberto.

Nada impede recordar, não obstante, de que a questão do monstro, e o monstro como questão, mesmo ambas obscuras, posto que infensas ao brilho purificador da luz, são e sempre foram proposições contemporâneas ao surgimento do homem como o ser das respostas. Que resplandecem todas as vezes em que ele, posto em questão, replica. E, como o Édipo que jamais deixou de ser, imagina ter resolvido, com a interrogação proposta pelo monstro, o enigma do monstro, e, de quebra, o enigma de sua própria existência.

É possível dizer que a questão do monstro, o monstro em questão e a resposta dada a elas, pelo homem, são coincidentes. Do alto de sua arrogância, o homem coloca a questão do outro, e com ela, ao invés de colocar-se em questão, assume-se como o mesmo de si, o sábio. Assim, ao responder, julga tê-la resolvido, ter-se resolvido. O fato de, na sequência, ele vir a se tornar o lobisomem, o lobo do homem ou a besta soberana, como argumentou Jacques Derrida ${ }^{2}$, tal fato apenas reforça a demonstração de que a resposta contém um erro inegável.

Se, como lembrou Maurice Blanchot, o homem é o indestrutível, e por isso não há limites para a sua destruição ${ }^{3}$, algo de análogo pode ser dito acerca do monstro. Com a condição de que ele fale, de que ele prossiga sua sina interrogante, que mantém na ordem do dia o enigma do humano. É possível daí compreender a oscilação ou polaridade das ações que os homens reservam para o monstro: de um lado, particularmente naquele que articula saber e poder, trata-se de compreendê-lo, classificá-lo e contê-lo, isto é, privá-lo de sua monstruosidade, destruí-lo. De outro lado, naquele que contempla em particular o campo das artes imaginativas, sejam de matiz popular ou erudita, trata-se de incessantemente reconstruí-lo, e inclusive criá-lo e recriá-lo, não raro como desvio da imagem e da semelhança tidas como próprias dos homens, e a partir de dejetos do corpo e da linguagem que estimam ser seus, em particular.

No terreno da imaginação, essa presença de monstros e monstruosidades pode ser observada em textos bastante longínquos, como a Epopeia de Gilgamesh, por exemplo, datada de pelo menos 2.000 anos a.C., na qual o herói batalha e vence gigantes e seres apavorantes, até sucumbir ao peso do tempo. Ou na Odisseia, que resgata a assinatura de Homero, em que Ulisses, ao se deparar ao longo de seu périplo com um dos monstros terríveis, nomeia-se como ninguém, logo antes de ludibriar Polifemo. Mas este sobrevive, mesmo ferido, deformado em sua monstruosidade mesma. No episódio pode-se ler, ao modo de 
uma alegoria: Ninguém elimina o monstro, justamente porque apenas esse tem o poder de transformar o ninguém que o derrota em alguém que será, adiante, reconhecido, e que assim poderá reassumir o governo de sua casa, de sua riqueza e dos seus. Um ninguém que, após suas aventuras, passa a saber que pode e sabe ser alguém, e, assim, retomar comando e controle.

$\mathrm{Na}$ medida em que prodígio, o monstro de-monstra. E ao mostrar-se ele nos mostra. E, claro, fascina e seduz, já que dotado de uma centelha de liberdade, para despeito nosso. Seja enquanto aberração física, sexual ou moral - que, tais como câncer, derruem desde dentro, ou, tais como lepra, corroem desde fora -, seja enquanto aberração da razão, ele de todo modo viola as leis, naturais, religiosas e sociais. O monstro, como bem definiu Michel Foucault, é uma das mais potentes modalidades do ser do excesso, aquele que, ao combinar "o impossível com o proibido"4, desafia e desmonta qualquer tentativa de classificação racional. É um dos emblemas do anormal, uma sorte de abjeta singularidade que escapa a todo regramento, a toda pretensão de domínio, de familiaridade. Daí a necessidade de conjurá-lo. E também daí, invertendo o foco, o encanto que dele emana, e que faz com que o tomemos como base ilusória para alimentar nossas próprias quimeras, e reafirmar todo nosso heroísmo humanista.

Mas se o monstro perverte o saber, a razão, por seu turno, não deixa de ser teimosa, e não se dá por vencida. Há que contê-lo, por certo, mas há também que explicá-lo, compreendê-lo. Caso isso não seja possível, é urgente afastá-lo, exterminá-lo. Mas ele retorna, sempre, posto que é uma de nossas obsessões. A idealização do monstro, de qualquer forma, não retira dele seu alcance simbólico. E tampouco a pulsão monstruosa que impulsa nossos desejos: pois o desejo é ele-mesmo monstruoso, insaciável e mutante, informe, sintomático.

Aby Warburg, em seu $A$ renovação da Antiguidade pagã, deixou-nos valiosos estudos nos quais discute fundamentos de práticas divinatórias que, ainda conhecidas na época da Reforma luterana, baseavam-se em configurações astrais para prever o aparecimento de monstruosidades e outras maravilhas ímpares. O cenário analisado, em especial em um dos ensaios do livro, "A antiga profecia pagã em palavras e imagens nos tempos de Lutero", tem como um de seus termos dominantes uma instigante anfibologia, em que misticismo, religião e racionalismo se combinam, em graus variáveis. Uma anfibologia na qual os humanos permanecemos imersos, de um modo ou de outro, graças à crescente reificação da política, algo por ele observado, que pouco a pouco vai tomar a forma da moderna bio-política.

É o que pode ser depreendido, por exemplo, na passagem que segue, em que o místico e o artístico são sutilmente
4. FOUCAULT, Michel. Os anormais (Curso no Collège de France: 1974-1975). Trad. Eduardo Brandão. São Paulo: Martins Fontes, 2001; p. 70. 
5. Aby Warburg, $A$ renovação da Antiguidade pagã (Contribuições científico-culturais para a história do Renascimento europeu). Trad. Markus Hediger. Rio de Janeiro: Contraponto/ MAR, 2013; p. 517.

\section{FOUCAULT, Michel. Os anormais (Curso no Collège de France: 1974-1975). Trad.} Eduardo Brandão. São Paulo: Martins Fontes, 2001; p. 71.

7. Ibidem, p. 32. articulados ao político: "encontramos na virada do século XV, tanto na Itália quanto na Alemanha, duas concepções contrárias da Antiguidade: a antiga concepção prático-religiosa e a nova concepção estético-artística. Enquanto essa parece se impor inicialmente na Itália e encontra alguns adeptos também na Alemanha, a Antiguidade astrológica vivencia na Alemanha um renascimento muito curioso que não tem sido suficientemente estudado. Os símbolos astrais que sobreviveram na literatura divinatória - principalmente os sete planetas antropomórficos - receberam uma injeção de sangue novo nas lutas desenfreadas do presente social e político que, de certa forma, os converteu em deidades políticas do momento. Além desses senhores do destino antropomórficos, que, como símbolos astrais, subjazem à interpretação astrológica metódica da profecia "artificial" (i.e., científica), em nossa análise também precisamos incluir os monstros terrestres como proclamadores do destino da adivinhação "prodigiosa""

Michel Foucault observa que o monstro "é o grande modelo de todas as pequenas discrepâncias. É o princípio de inteligibilidade de todas as formas - que circulam na forma de moeda miúda - da anomalia" ${ }^{6}$. É em contraposição a esse perigo representado pelo monstro, cujo poder é o de virtual e atualmente desestabilizar, desde dentro, a oikonomia das sociedade ocidentais, que Foucault identifica a emergência de técnicas de disciplinarização, de um "poder de normalização" que se forma e se instala de modo tentacular, "sem jamais se apoiar numa só instituição, mas pelo jogo que conseguiu estabelecer entre diferentes instituições", processo através do qual obtém sucesso em estender "sua soberania em nossa sociedade"

Uma das respostas possíveis a uma situação asfixiante como tal, em que, na perspectiva unitária do bio-poder, somos todos potencialmente monstros ou monstruosos, pode ser dada por um fazer artístico e um pensamento que assumam o caráter radical da própria situação em que nos encontramos. É o que propõe, entre outros, Georges Bataille, em seu elogio à crueldade, quando postula o exercício de uma "embriaguez multiplicada”. Não se trata, como ele esclarece, de propor uma "apologia dos feitos horríveis. (...) Mas, no atoleiro inexplicável no qual nos movemos, em algum sentido esses momentos resplandecentes (...) trazem consigo, no instante do rapto, toda a verdade da emoção. Porque de todas maneiras a emoção, caso nela se inscreva o sentido da vida, não pode ser subordinada a nenhuma obra útil. Assim, o paradoxo da emoção sustém que seu sentido será maior quanto menos sentido tenha. A emoção que não está ligada à abertura do horizonte, mas a um objeto estreito, a emoção dentro dos limites da razão nos propõe nada mais que uma vida encolhida. Carregada com nossa verdade perdida, a 
emoção é proclamada em desordem, tal como a imagina a criança quando compara a janela de seu quarto com a profundidade da noite. $\mathrm{A}$ arte, sem dúvida, não está obrigada à representação do horror; mas seu movimento a situa, sem prejuízo, à altura do pior e, reciprocamente, a pintura do horror revela a abertura a todo o possível"8.

Ou, nos termos de César Aira, trata-se de garantir a imortalidade dos monstros, mesmo que seja ao preço de confiná-lo aos terrenos do lendário e do artístico: "O monstro é único, não tem com quem se casar nem com quem procriar descendência. O monstro é sempre como que um símbolo da extinção, porque o monstro constitui uma espécie, mas uma espécie constituída por um só indivíduo... Por isso costuma-se dar-lhe o dom da imortalidade, costuma-se fazê-lo sobreviver de alguma maneira distinta daquela que nós encontramos, que é a de nos reproduzirmos, e por isso os monstros têm, enfim, essa melancolia do ser que se sabe condenado a uma extinção definitiva, mas que não é de todo definitiva: a posteridade do monstro é sua legenda. Nisso o monstro é um ente quase artístico, porque o único que pode deixar é a história que foi"’.

Diante deste quadro, os ensaios que seguem, tendo por foco diferentes textualidades habitadas por diversos seres prodigiosos, podem ser lidos como casos em que a situação extrema colocada por monstros e monstruosidades nos afeta. Boa leitura.
8. Georges Bataille, "El arte, ejercicio de crueldad", La felicidad, el erotismo y la literatura (Ensayos: 1944-1961), tradução de Silvio Mattoni, Buenos Aires: Adriana Hidalgo, 2004; p. 124-125 (tradução nossa). Eis a passagem, na tradução ao espanhol: "No hago la apología de los hechos horribles. (...) Pero en el atolladero inexplicable donde nos movemos, en algún sentido esos momentos resplandecientes (...) traen consigo en el instante del rapto toda la verdad de la emoción. Porque de todas maneras la emoción, si en ella se inscribe el sentido de la vida, no puede ser subordinada a ninguna obra útil. Así, la paradoja de la emoción sostiene que su sentido será mayor cuanto menos sentido tenga. La emoción que no está ligada a la apertura del horizonte sino a un objeto estrecho, la emoción dentro de los límites de la razón no nos propone más que una vida encogida. Cargada con nuestra verdad perdida, la emoción es proclamada en desorden, tal como la imagina el niño comparando la ventana de su pieza con la profundidad de la noche. El arte, sin duda, no está obligado a la representación del horror; pero su movimiento lo ubica sin perjuicio a la altura de lo peor y, recíprocamente, la pintura del horror revela la apertura de todo lo posible".

9. César Aira, verbete em "Diccionario inconcluso del narrador latino-americano actual", Boletín de reseñas bibliográficas, n 9/10, Facultad de Filosofía y Letras, UBA, 2006; p. 337 (tradução nossa). Eis a passagem, no original: "El monstruo es único, no tiene con quién casarse ni con quién procrear descendencia. El monstruo es siempre como un símbolo de la extinción, porque el monstruo contituye una especie, pero una especie 
constituída por un solo

individuo... Por eso se les suele dar el don de la inmortalidad, se los suele hacer sobrevivir de algún modo distinto del que encontramos nosotros, que es el de reproducirnos, y por esto los monstruos tienen, en fin, esa melancolía del ser que se sabe condenado a una extinción definitiva, pero que no es del todo definitiva: la posteridad del monstruo es su leyenda.

En eso el monstruo es un ente casi artístico, porque lo único que puede dejar es la historia que fue". 